\section{FABRICATION AND CHARACTERIZATIONS OF GELATIN/CHITOSAN WITH ALOE VERA AND ACHATINA FULICA SP MUCUS AS SCAFFOLD FOR SKIN TISSUE ENGINEERING}

\author{
Prihartini Widiyantia,b*, Fathania Nabillaa, Dyah Hikmawatic
}

aBiomedical Engineering, Faculty of Science and Technology, Universitas Airlangga, Surabaya, Indonesia

bInstitute of Tropical Disease Center, Universitas Airlangga, Surabaya, Indonesia

cDepartment of Physics, Faculty of Science and Technology, Universitas Airlangga, Surabaya, Indonesia
Article history

Received

4 March 2018

Received in revised form

31 March 2019

Accepted

17 April 2019

Published online

25 June 2019

*Corresponding author pwidiyanti@fst.unair.ac.id

\begin{abstract}
Scaffold is a biomaterial widely used in tissue engineering. Scaffold is temporary porous structure which contain extracellular matrix. It serves as scaffolding which is required for cells infiltration and physical support to guide the cell proliferation and differentiation into the targeted functional tissues. Scaffold must be biocompatible, small pore size, flexible and support regenerative application. Aloe vera as natural resource, it has capability in accelerating wound healing, facilitating the inflammation, increasing wound contraction and epithelialization, and increasing organization of the regenerated tissue. Snail mucus (SM) has capability in inhibiting bacterial growth. This study aims to synthesize and characterize a scaffold made of gelatin-chitosan-Aloe vera (AV) - Achatina fulica sp mucus. The method is to synthesize scaffold with its compositions, gelatinchitosan (1: 1 ratio) which is dissolved into $0.05 \mathrm{M}$ acetic acid, then a variation of Aloe vera (AV) and snail mucus (SM) at $0 \%$ $\mathrm{AV} ; 0 \%$ SM; $0.07 \mathrm{AV} ; 0.07 \mathrm{SM} ; 0.15 \mathrm{AV} ; 0.15 \mathrm{SM} ; 0.07 \mathrm{AV} ; 0.15 \mathrm{SM} ; 0.15 \mathrm{AV} ; 0.007$ SM were mixed with the chitosan-gelatin solution, then used freeze dry method to obtain porous scaffold. Characterization which performed in this research including Fourier-transform infrared spectroscopy (FTIR), Scanning Electron Microscopy (SEM), porosity test, tensile strength test, swelling test, and degradation test. Based on FTIR test, Aloe vera and snail mucus interacted with free amino and hydroxyl groups of chitosan and gelatin, characterized by absorption bands at $2937.59 \mathrm{~cm}-1$ wave numbers which are symmetrical and asymmetrical stretching of $(-\mathrm{CH})$.SEM test results obtained pore size of $70-235 \mu \mathrm{m}$. Porosity test results showed that five scaffolds have porosity value of $87-96 \%$; thus, allowing the process of cell proliferation to occur well. The result of physical characteristic test yielded tensile strength of $1.425 \mathrm{MPa}$ on gelatin-chitosan as control sample and $0.732 \mathrm{MPa}$ for sample with $0.15 \% \mathrm{AV}$ and $0.15 \% \mathrm{SM}$. Swelling test showed a variation of scaffold composition with Aloe vera with Achatina fulica sp's mucus having a swelling percentage of $200-520 \%$. The degradation test results showed that the whole sample was not depleted for 21 days; thus, giving time for cell regeneration. Sample with $0.15 \%$ Aloe vera and $0.07 \%$ snail mucus has some potentials as scaffolds for skin tissue in case of burns wound, due to its morfology, porosity, and degradation.
\end{abstract}

Keywords: Scaffold, gelatin, chitosan, Aloe vera, snail mucus, burns

(C) 2019 Penerbit UTM Press. All rights reserved

\subsection{INTRODUCTION}

High prevalence level of skin loss due to burn cases needs some regeneration process to return the skin's main function, namely protect the body, organize some physiology features like temperature, and function as sensory system [1]. World Health Organization (WHO) also notes that burns are a global public health problem, accounting for an estimated 180000 deaths annually [2]. For third degree burns, the wound is too deep and damages organs under the skin, such as muscles, nerves, 
bones; moreover, it could not recover spontaneously due to the proliferation of its epithelial layer (reepithelialization) at the edge of the wound does not occur [3].

The most effective third degree burns healing process requires the role of a scaffold as an important factor in tissue engineering. Scaffold is a temporary porous buffer material in which there is an extracellular matrix functioning as a scaffold for infiltration and physical support to guide cell differentiation and proliferation into targeted functional tissues [4].

Biocomposite of these material is potential to be developed as scaffold for tissue engineering in burn cases, particularly gelatin which has several commercially available properties at low cost, biodegradable, and biocompatibility [5], as well as chitosan which has been widely applied in various biomedical applications, such as tissue engineering and regenerative drugs due to their non-toxic and biocompatible properties [6]. Adding Aloe vera can hydrate skin, as it contains anti-inflammatory material [7], while adding Achatina fulica sp's mucus with its anti-bacterial factor can work by attacking or inhibiting the formation of bacterial strains' common parts, such as peptidoglycan layers and cytoplasmic membranes [8].

The ideal scaffold for tissue engineering applications should be biocompatible, has large surface ratios, large volumes, small pore size to control degradation, flexible in mechanical properties, and biologically safe and support medical applications due to organ replacement in order to support regenerative treatment [9]. Suitable micro-scaffold structures, such as average pore size of $63-150 \mu \mathrm{m}$ and porosity values above 90\% [10] has some appropriate mechanical properties, including elongation and tensile strength [11, 12]. The characterizations used include Fourier Transform Infra Red Spectroscopy (FTIR) test, Scanning Electron Microscope (SEM) test, porosity test, tensile strength test, swelling test, and degradation test. Previous research on scaffold synthesis based on gelatine and chitosan was performed by Kakkar at 2014 [13]. In his study, the scaffold mechanical value is less elastic. It is not applicable for skin substitute, because it needs appropriate tensile strength, flexibility and elasticity. In this research, he added Aloe vera and snail mucus to create anti-inflammatory and pain relief scaffold, and glycerol for better flexibility and elasticity.

\subsection{METHODOLOGY}

\section{Materials}

Gelatin, Phosphate Buffer Saline (PBS), acetic acid, $\mathrm{NaOH}$ solution, glycerol, Ethanol, $\mathrm{NaBH}_{4}$ solution from UD.SIP (Surabaya, Indonesia), chitosan (DD = 85\%) from Sigma Aldrich, snail mucus (Achatina fulica sp's mucus), Aloe vera extract (Aloe vera), glutaraldehyde from PT. Kristalindo (Surabaya, Indonesia). Magnetic bar, magnetic stirrer, incubator, freeze dryer, FTIR test tool (8400 Shimadzu), SEM test tool (FEl, Inspect S50 Jepang), and Tensile Strength test equipment (Autograph Imada HV-500 NII).

This study used 3 variables, which are control variables ( $2 \%$ gelatin and $1 \%$ Chitosan), independent variables (Aloe vera concentration and snail mucus at ratio (0.07: 0.07; 0.15: 0.15; 0.07: 0.15; 0.15: $0.07 \mathrm{w} /$ v), and dependent variables (gelatin/chitosan-based biocomposites characteristic with Aloe vera extract and snail mucus as the scaffolds).

\section{Methods}

Preparing gelatin-chitosan-Aloe vera-snail mucus scaffold is initially conducted by mixing $2 \%$ gelatin solution and $1 \%$ Chitosan solution with 1: 1 ratio using magnetic stirrer at $500^{\circ} \mathrm{C}$ for 2 hours. The incorporation of Aloe vera and snail mucus into scaffolds based on gelatin and chitosan is tend to alter the structure, composition and biodegradability property, as good as the potential effect on bioactivity. Aloe vera (A) and snail mucus (S) blended Gelatine (G)-Chitosan (Ch) composite was formulated by mixing different weighted quantities of $A$ and $S$ with the $\mathrm{G}-\mathrm{CH}$ solution to obtain a final concentration Aloe vera and snail mucus extracts with various concentrations 0:0 (Sample A), 0.07: 0.07 (Sample B), 0.15: 0.15 (Sample C), 0.07: 0.15 (Sample D), 0.15: 0.07 (Sample E) (W/ v) are added along with $0.3 \%$ Glycerol. After homogeneously mixing it, the authors leave it over for 2 hours inside liquid nitrogen chamber at $-190^{\circ} \mathrm{C}$. Then, it is frozen and dried at $580^{\circ} \mathrm{C}$ for 18 hours and placed in a desiccator with $10 \%$ gluteraldehyde in $90 \%$ ethanol. After that, the sample is immersed in $1 \% \mathrm{NaOH}$ solution, washed twice with distilled water, and dipped in $5 \%(\mathrm{w} / \mathrm{v})$ $\mathrm{NaBH} 4$. Finally, the scaffold was frozen at $-190^{\circ} \mathrm{C}$ and frozen-dried for 18 hours. Sample $A$ with no addition of Aloe vera and Snail mucus, Sampel B - E with addition of Aloe vera and snail mucus concentration (0.07: 0.07; 0.15: 0.15; 0.07: 0.15; 0.15: $0.07 \mathrm{w} / \mathrm{v}$ ) subsequently are finally characterized. The size of sample for FTIR test, SEM, degradation test, porosity test, swelling test are $1 \times 1 \mathrm{~cm}$ in sheet form, for tensile strength $5 \times 1 \mathrm{~cm}$ in sheet form. Furthermore, the characterizations for FTIR test, Scanning Electron Microscope (SEM) test, porosity test, tensile strength test, swelling test, and degradation test are performed. There was 3 times repetition for this experiment.

\subsection{RESULT AND DISCUSSION}

\section{Functional Groups Result}

The aliphatic group $\left(-\mathrm{CH}_{2}\right.$ and $\left.-\mathrm{CH}_{3}\right)$ can be seen in the absorption of wave number $2939.52 \mathrm{~cm}^{-1}$ in sample A, $2937.59 \mathrm{~cm}^{-1}$ in sample B, $2937.58 \mathrm{~cm}^{-1}$ 
in sample C, $2937.59 \mathrm{~cm}^{-1}$ in sample D, and $2939.52 \mathrm{~cm}^{-1}$ in the sample E. At absorption peak of wave number $1658.78 \mathrm{~cm}^{-1}$ in sample $A, 1658.78$ $\mathrm{cm}^{-1}$ in sample $\mathrm{B}, 1653 \mathrm{~cm}^{-1}$ in sample $\mathrm{C}, 1658.78$ $\mathrm{cm}^{-1}$ on sample $\mathrm{D}$, and $1664.57 \mathrm{~cm}^{-1}$ on sample $\mathrm{E}$ has a $C=O$ stretching functional group. At absorption of wave number of $1546.91 \mathrm{~cm}^{-1}$ in sample A, $1544.98 \mathrm{~cm}^{-1}$ in sample $B, 1546.91 \mathrm{~cm}^{-1}$ in sample C, $1544.98 \mathrm{~cm}^{-1}$ in sample $D$, and 1543.05 $\mathrm{cm}^{-1}$ on sample $\mathrm{E}$ is $-\mathrm{NH}_{2}$ bending. The absorption of wave number $1154.44 \mathrm{~cm}^{-1}$ in sample $\mathrm{A}, 1145.72$ $\mathrm{cm}^{-1}$ in sample $\mathrm{B}, 1161.14 \mathrm{~cm}^{-1}$ in sample $\mathrm{C}$, $1161.14 \mathrm{~cm}^{-1}$ in sample $D$, and $1130.29 \mathrm{~cm}^{-1}$ in the sample $\mathrm{E}$ is -COC-glycosidic relationship between chitosan monomers. The presence of C-O stretching groups from the primary alcohol group is shown in the absorption of wave number $1058.92 \mathrm{~cm}^{-1}$ in sample A, $1056.99 \mathrm{~cm}^{-1}$ in sample $\mathrm{B}, 1072.42 \mathrm{~cm}^{-1}$ in sample $\mathrm{C}, 1076.28 \mathrm{~cm}-1$ in sample D, and $1031.92 \mathrm{~cm}^{-1}$ in sample $\mathrm{E}$. The typical peak of gelatin absorption is shown in the absorption of wave numbers $3392.79 \mathrm{~cm}^{-1}$ in sample A, $3346.5 \mathrm{~cm}^{-1}$ in sample $B, 3429.43 \mathrm{~cm}^{-1}$ in sample $C, 3433.29 \mathrm{~cm}^{-1}$ in sample $D$, and 3346.5 $\mathrm{cm}^{-1}$ in sample $\mathrm{E}$, which is a group of hydroxyl groups (-OH) (as seen in Figure 1). The peak of the amine group for pure chitosan in the study conducted by Ahmad, et al., 2011 was 1643 and $1584 \mathrm{~cm}^{-1}$ then shifted to 1658.78 and $1546.91 \mathrm{~cm}^{-1}$ in the gelatin / chitosan composite in sample $A$; $1664.57 \mathrm{~cm}^{-1}$ and $1543.05 \mathrm{~cm}^{-1}$ in sample $\mathrm{B} ; 1653$ $\mathrm{cm}^{-1}$ and $1546.91 \mathrm{~cm}^{-1}$ in sample $C ; 1658.78 \mathrm{~cm}^{-1}$ and $1544.98 \mathrm{~cm}^{-1}$ in sample D; and $1664.57 \mathrm{~cm}^{-1}$ and $1543.05 \mathrm{~cm}^{-1}$ in sample $\mathrm{E}$ in accordance with the vibration of amine bonds in chitosan. Then the peak of the amino group and hydroxyl group becomes wider and deeper indicating the possibility of Aloe vera and snail mucus which is interacted with free amino and hydroxyl groups of Chitosan and Gelatin, this is indicated by the absorption band at wave number $2937.59 \mathrm{~cm}^{-1}$ in sample B, $2937.58 \mathrm{~cm}^{-1}$ in sample C, $2937.58 \mathrm{~cm}^{-1}$ in sample D; and $2939,52 \mathrm{~cm}^{-1}$ in sample $E$ which is a symmetrical and asymmetrical $\mathrm{C}-\mathrm{H}$ stretching from $(-\mathrm{CH})$ which marks the presence of a Piranose Ring. There are also wave number absorption at $1238.30 \mathrm{~cm}^{-1}$ in sample $\mathrm{B}, 1249.87$ $\mathrm{cm}^{-1}$ in sample $C, 1249.87 \mathrm{~cm}^{-1}$ in sample $\mathrm{D}$, and $1253.73 \mathrm{~cm}^{-1}$ in sample $\mathrm{E}$ which is a $\mathrm{CO}$ stretching group of Ester and Phenol groups so that the spectrum of the sample with the addition of Aloe vera and Snail mucus extract becomes sharper, and there are also absorption of wave numbers at $1031.92 \mathrm{~cm}^{-1}$ in sample B, $1031.92 \mathrm{~cm}^{-1}$ in sample C, $1037.7 \mathrm{~cm}^{-1}$ in sample $\mathrm{D}$, and $1031.92 \mathrm{~cm}^{-1}$ in sample $\mathrm{E}$ which are $\mathrm{C}-\mathrm{O}$ stretching from polysaccharides in Aloe vera and Snail mucus [14].

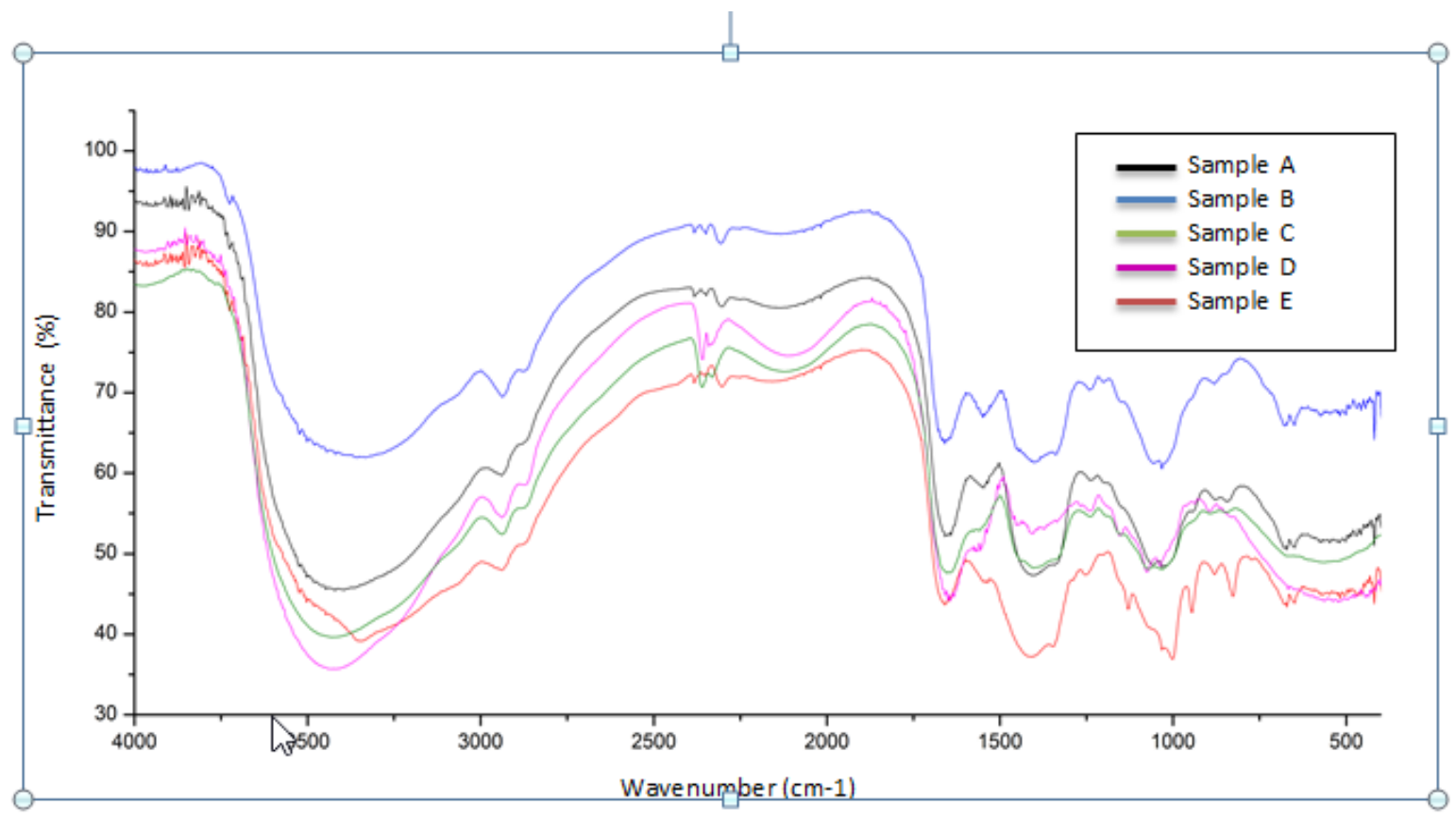

Figure 1 FTIR Spectra of Samples A (0\%AV, 0\% SM), B (0,07\%AV, 0,07\% SM), C(0,15\%AV, 0,15\% SM), D (0,07\%AV, 0,15\% SM), E $(0,15 \%$ AV, $0,07 \%$ SM)

The peak absorption of $\mathrm{NH}$ stretching group which marks the presence of Amida A group, is not seen in this infrared spectra due to the overlap of absorption spectra with $\mathrm{OH}$ stretching groups. At wave number absorption $1658.78 \mathrm{~cm}^{-1}$ in sample A, $1658.78 \mathrm{~cm}^{-1}$ in sample $\mathrm{B}, 1653 \mathrm{~cm}^{-1}$ in sample $C, 1658.78 \mathrm{~cm}^{-1}$ in sample $D$, and 1664.57 $\mathrm{cm}^{-1}$ in sample $\mathrm{E}$ there is Amida I. The presence of Amida II is indicated by the absorption of wave numbers $1546.91 \mathrm{~cm}^{-1}$ in sample A, $1544.98 \mathrm{~cm}^{-1}$ in 
sample $B, 1546.91 \mathrm{~cm}^{-1}$ in sample C, $1544.98 \mathrm{~cm}^{-1}$ in sample D, and $1543.05 \mathrm{~cm}^{-1}$ in sample $\mathrm{E}$. The Cross link of $\mathrm{C}=\mathrm{O}$ group of gelatin with $\mathrm{NH}$ group of chitosan indicates the interaction between Chitosan and Gelatin, thus increasing the intensity of $\mathrm{NH}$ bending group at a peak of $3392.79 \mathrm{~cm}^{-1}$ in sample $A, 3346.5 \mathrm{~cm}^{-1}$ in sample $B, 3429.43 \mathrm{~cm}^{-1}$ in sample C, $3433.29 \mathrm{~cm}^{-1}$ in sample D, and 3346.5 $\mathrm{cm}^{-1}$ in sample $\mathrm{E}$. The peak of the amino group and hydroxyl group becomes wider and deeper indicates the possibility of Aloe vera and snail mucus are interacted with free amino and hydroxyl groups from chitosan and gelatin only in samples B, C, D, and E, indicated by the absorption band at wave numbers $2937.59 \mathrm{~cm}^{-1}$ in sample $B, 2937.58 \mathrm{~cm}^{-1}$ in the sample C, 2937.59 $\mathrm{cm}^{-1}$ in sample $\mathrm{D}$, and $2939.52 \mathrm{~cm}^{-1}$ in sample $\mathrm{E}$, which is a symmetrical and asymmetrical $\mathrm{C}-\mathrm{H}$ stretching from $(-\mathrm{CH})$ which marks the presence of a Pyranose Ring. Then there is the absorption of wave number $1238.20 \mathrm{~cm}^{-1}$ in sample $B, 1249.87$ $\mathrm{cm}^{-1}$ in sample $C, 1249.87 \mathrm{~cm}^{-1}$ in sample $\mathrm{D}$, and $1253.73 \mathrm{~cm}^{-1}$ in sample $\mathrm{E}$ which is a $\mathrm{CO}$ stretching group of Ester and Phenol groups so that the spectrum in the sample with an addition Aloe vera and snail mucus extracts become sharper. There is also the absorption of wave numbers at $1031.92 \mathrm{~cm}^{-1}$ in the sampleB, $1031.92 \mathrm{~cm}^{-1}$ in samples $C, 1037.70 \mathrm{~cm}^{-1}$ in sample $D$, and 1031.92 $\mathrm{cm}^{-1}$ in sample $\mathrm{E}$, which is a C-O stretching of polysaccharides in Aloe vera and Snail mucus [14]. Based on the functional group test, Chitosan / Gelatin scaffold with variation of Aloe vera and snail mucus is showed the occurrence of Gelatin and Chitosan binding. This can be proven based on the mixture of absorption characteristics of amine group of chitosan and carboxylic acid group of gelatin.

\section{Morphological Analysis}

SEM test aims for morphology test to examine surface structure, pore diameter, porous layer, non-porous layer, and membrane thickness [15]. The samples were placed on a holder and inserted into a recorder tool to be subsequently displayed on computer screen, as shown in Figure 2.

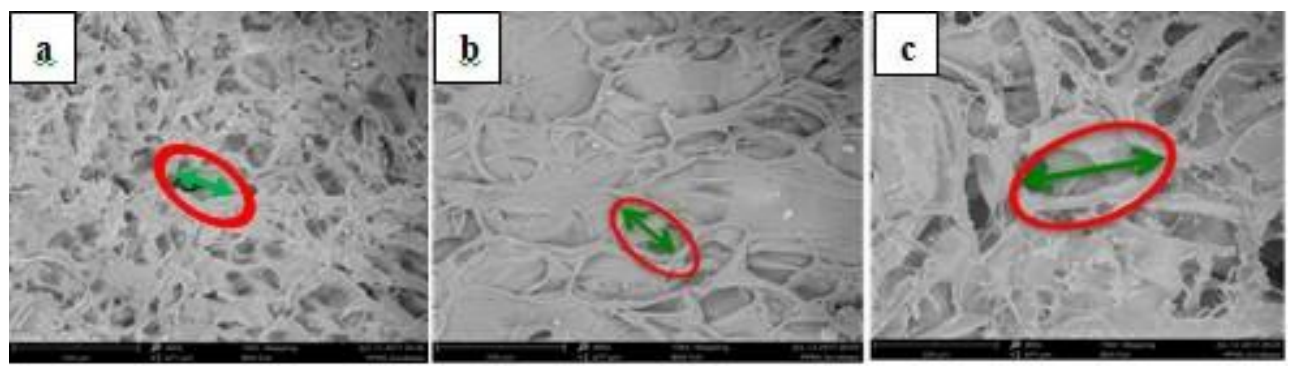

Figure 2 (a) SEM result of sample with concentration of Aloe vera and snail mucus 0.15: $0.07 \mathrm{w} / \mathrm{V}$ (sample E)(b) SEM result of sample with concentration of Aloe vera and snail mucus (sample A) (A) $0: 0 \mathrm{w} / \mathrm{v}$ (control). (c) SEM result of sample with concentration of Aloe vera and snail mucus 0.07: $0.07 \mathrm{w} / \mathrm{V}$ (sample B)

The sample used in the test were the sample with various concentration of Aloe vera and snail mucus, which are sample sample A $(0: 0 \mathrm{w} / \mathrm{v})$, sample $B$ $(0,07: 0,07 \mathrm{w} / \mathrm{v})$ and sample E (0.15: $0.07 \mathrm{w} / \mathrm{v})$. The calculation of pore size in SEM using measurement from the scale bar (reference length). SEM test results of the scaffold surface pore sizes recorded an average value of $117.3 \pm 1,8 \mu \mathrm{m}$ for sample $\mathrm{A}, 206.3 \pm$ $1,7 \mu \mathrm{m}$ for sample $\mathrm{B}$ and $78.5 \pm 1,03 \mu \mathrm{m}$ for sample $\mathrm{E}$. The best sample with various concentration of Aloe vera and snail mucus is 0.15: $0.07 \mathrm{w} / \mathrm{v}$. As shown in Figure 2 sample $\mathrm{E}$ has smaller pore sizes than sample A (control) and sample B. The pore sizes used in scaffold applications were 63 - 150 um [10], the pores were in the range for scaffold applications, which is better if it is compared to the previous research by Angulo and Sobral [14] with the pore size 93-296 $\mu \mathrm{m}$. The addition of Aloe vera and snail mucus increases average pore size and porosity and causes some changes in pore architecture [16]. However, the decrease in pore size as the concentration of Aloe vera increases in sample $\mathrm{E}$ can be caused by the Aloe vera content with macromolecules into the mixed system [23].

\section{Porosity Analysis}

Porosity test aims to determine the level of scaffold porosity using fluid transfer method at $25^{\circ} \mathrm{C}$ with Pycnometer. Absolute ethanol is used as a displaced fluid, because it could easily penetrate the scaffold and not trigger either shrinking or swelling. The porosity value was obtained through weight calculation using the predetermined equation. Analyses of porosity, were performed in triplicate/three times. Based on Figure 3, the control sample recorded porosity value of $80 \%$ and the porosity of scaffold with Aloe vera and snail mucus recorded porosity ranges of $87-96 \%$. While the data of porosity of each sample are sample A $80 \% \pm 1$, sample B $96 \% \pm 1$, sample C $89 \pm 1$, sample D $87 \% \pm$ 1,5 , sample $\mathrm{E} 94 \% \pm 1$. The condition of porosity result 
are corresponded to a fairly high porosity range which possibly to facilitate cell proliferation .The outer thick layer of Aloe vera, or rind, comprised of 15-20 cells, has a protective function and synthesizes carbohydrates and proteins. Vascular bundles inside the rind are composed of xylem and phloem [2]. Xylem helps to transport water and minerals from roots to leaves and phloem helps to transport starch and other small organic molecules [23]. AV and snail mucus have shown excellent porosity and biological properties.Polysaccharides which are provided by Aloe vera and snail mucus can improve the material porosity, by allowing entry for water [14].

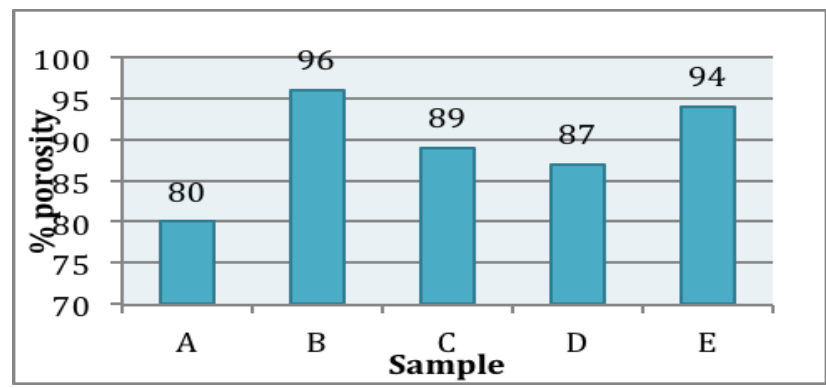

Figure 3 (a) Porosity test results of sample A (0\%AV, 0\% SM), B (0,07\%AV, 0,07\% SM), C (0,15\%AV, 0,15\% SM), $\mathrm{D}(0,07 \% \mathrm{AV}, 0,15 \% \mathrm{SM}), \mathrm{E}(0,15 \% \mathrm{AV}, 0,07 \% \mathrm{SM})$

\section{Tensile Strength Test}

Tensile strength test aims to determine tensile strength of the scaffold. Determination of mechanic characteristic was conducted by cutting the scaffold in dumbbell shape. The data obtained are elastic boundary information $(\sigma E)$, tensile strength, and strain. Based on the measurement, voltage curve and strain were obtained. Strain strength is a maximum pull which is achievable until the material can survive and tear. Material's stiffness can be analyzed through the calculation of the young modulus which is the ratio between tensile strength and strain. The mechanical test was performed using Autograph tool. From the tensile strength, a value of $1,425 \mathrm{MPa}$ for tensile strength was performed from sample A /control. The highest value of tensile strength was refer to control sample. The tensile strength value of samples are sample A 1,425 \pm 0,0025, sample B $0,082 \pm 0,0203$, sample C 0,732 \pm 0,0015, sample D 0,475 $\pm 0,0057$, sample E 0,620 \pm 0,0058 . While the values of tensile strength in the sample $B, C, D, E$ with Aloe vera and snail mucus concentration $0,07 \% \mathrm{AV}: 0,07 \%$ SM; $0,15 \% \mathrm{AV}: 0,15 \%$ SM; $0,07 \%$ AV $: 0,15 \% \quad S M ; \quad 0,15 \% \quad$ AV: $0,07 \% \quad S M$ subsequently, as illustrated in Figure 4.

Sample B has lowest tensile strength value due to the big pore size. Previous research by Angulo dan Sobral, scaffold with addition snail mucus has lower tensile strength compare with control. This might be related with functional group $\mathrm{C}-\mathrm{O}$ and $-\mathrm{COOH}$. Type of polymer and ionic characteristic could yield lower molecules interaction and alter the elasticity [14].
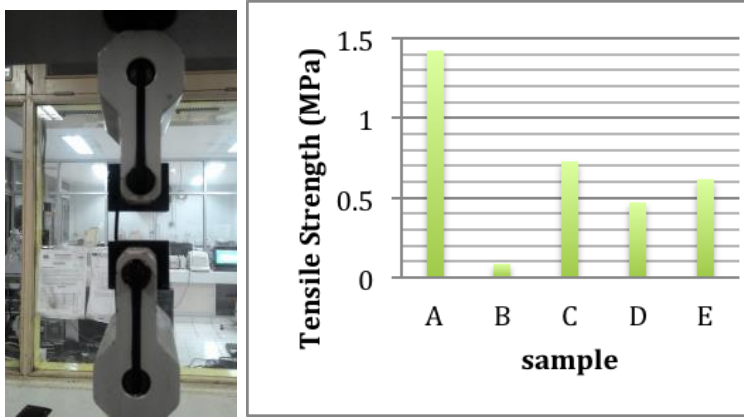

Figure 4 (a) Tensile strength test process; (b) Result tensile strength test Samples A (0\%AV, 0\% SM), B (0,07\%AV, 0,07\% $S M), C(0,15 \% A V, 0,15 \%$ SM) $D(0,07 \% A V, 0,15 \%$ SM $), E(0,15 \%$ $A V, 0,07 \%$ SM)

\section{Swelling Test Analysis}

Swelling test aims to determine the ability of water retention from scaffold, by soaking the samples in Phospate Buffered Saline (PBS). Analyses of swelling were performed in triplicate/three times. At the first, second, seventh, and fourteenth day, the samples are weighted and calculated to obtain swelling percentage, as illustrated in Figure 5. The swelling value of samples are sample A-E in $1^{\text {st }}$ day $604 \% \pm 1$; $278 \pm 1,15 ; 263 \pm 1,15 ; 259 \pm 0,58 ; 261 \pm 0,58$ subsequently, in $2^{\text {nd }}$ day $579 \pm 1 ; 341 \pm 0,58 ; 318 \pm$ 1,$53 ; 313 \pm 0,58 ; 314 \pm 0,58$ subsequently, in $7^{\text {th }}$ day 563 $\pm 0,58 ; 381+1 ; 338+1,73 ; 332 \pm 1,15 ; 334 \pm 1,53$ subsequently, in $14^{\text {th }}$ day $560 \pm 1,5 \overline{5} ; 520 \pm 1 ; 3 \overline{39} \pm 1$; $336 \pm 1,15 ; 337 \pm 1,15$ subsequently. In this research, the swelling value reached $200-520 \%$ which was close to the swelling value in the research of Rose et al. at 2013 [23], which had reached 300-400\%. The samples contained Aloe vera recorded lower swelling value compare with sample without Aloe vera. It might be caused by the affinity and good interaction between the matrix and scaffold with Aloe vera which can actually decrease water binding capability. The water uptake of scaffold decreased with increase in the concentration of the crosslinker used. The equilibrium swelling of scaffold also decreased with increase in the content of gelatin as crosslinker. Short crosslinking time resulted in material, which was characterized by a rapid increase in the swelling of material in the first 4 hours, followed by a collapse of network structure. Increasing the crosslinking time resulted in a decrease in the swelling capacity of the material because of the formation of a higher density of crosslinking points in the network structure [24]. 


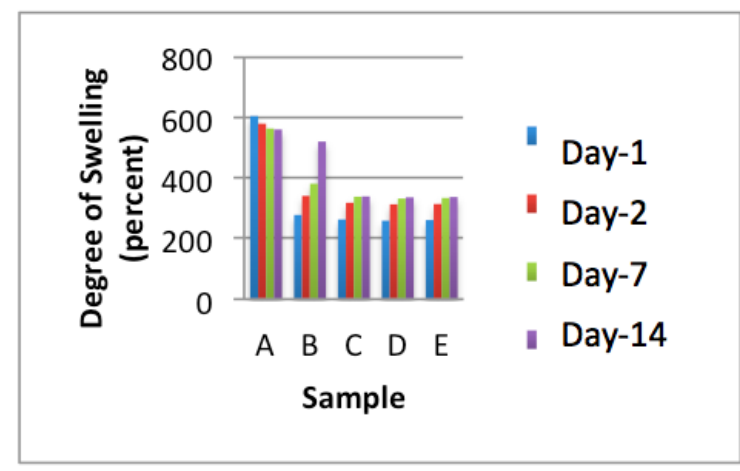

Figure 5 (a) Swelling test results of Samples A (0\%AV, 0\% SM), B $(0,07 \% A V, 0,07 \%$ SM) $, C(0,15 \% A V, 0,15 \%$ SM $), D(0,07 \% A V$ $0,15 \%$ SM), E ( 0,15\% AV, 0,07\% SM

\section{Degradation Test Analysis}

Degradation is the physical (or sometimes chemical) deterioration of a compound due to external chemical exposure or ambient conditions. Degradation test aim is to discover how long it takes for a sample to decompose in the body, so that the cell could produce an extracellular matrix [25]. Therefore, degradation character of the scaffold is essential to select and design biomaterials, as well as for the long-term success of tissue engineering [16].

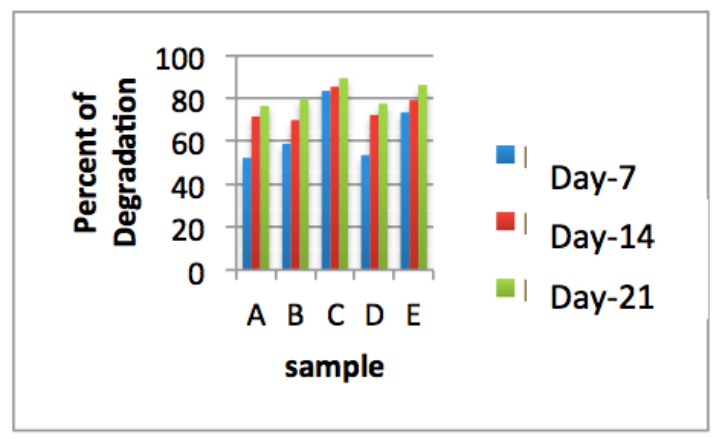

Figure 6 (a) Degradation test result of Samples A (0\%AV, 0\% SM), B (0,07\%AV, 0,07\% SM), C(0,15\%AV, $0,15 \%$ SM), $\mathrm{D}(0,07 \% \mathrm{AV}, 0,15 \% \mathrm{SM}), \mathrm{E}(0,15 \% \mathrm{AV}, 0,07 \% \mathrm{SM})$

The samples are immersed in Phosphate Buffered Saline (PBS) solution resembling body fluids. Then, a percentage of weight less was calculated at a given time, such as the $7^{\text {th }}, 14^{\text {th }}$ and $21^{\text {st }}$ day. The value of degradation of sample $A-E$ in $7^{\text {th }}$ day are $52,16 \pm$ 1,$06 ; 58,67 \pm 0,89 ; 83,29 \pm 1,01 ; 53,4 \pm 1,07 ; 73,3 \pm 1,29$ subsequently, in $14^{\text {th }}$ day $71,37 \pm 1,4 ; 69,72 \pm 1,8 ; \overline{8} 5,27$ $\pm 1,77 ; 72,14 \pm 1,42 ; 79,04 \pm 1,11$ subsequently, $1 \mathrm{n} 21^{\mathrm{st}}$ day 76,31 $\pm 1,06 ; 79,3 \pm 1,66 ; 89,26 \pm 1,13 ; 77,41 \pm 1,07$; $86,10 \pm 1,51$ subsequently. Analyses of degradation were performed in triplicate/three times. Based on Figure 6 , after the $21^{\text {st }}$ day of incubation process, scaffold was degraded over $70 \%$ to $90 \%$, proving its biodegradable character in a body fluid-like circumstance. Based on the degradation test results, on the $21^{\text {st }}$ day, the samples are not $100 \%$ degraded, they met the standards of scaffolds for burns cases, because skin regeneration period in burns cases needed 21 days or more to recover [26] so good scaffold should not $100 \%$ degraded before the $21^{\text {st }}$ day.

\subsection{CONCLUSION}

Characteristics of gelatin / chitosan with Aloe vera and Achatina fulica sp mucus biocomposite in skin tissue engineering in the burn case are showed in FTIR that there has been a bond between the chitosan with gelatin and aloe vera with the Achatina fulica sp mucus. While the pore size, porosity and swelling value of biocomposite scaffold meet up with application standard. Eventhough the tensile strength $s$ are still need to optimized. The degradation time of this biocomposite scaffold is 21 days, compatible with standard. Gelatin-chitosan Biocomposites, along with the addition of Aloe vera and snail mucus extracts is potentially used as scaffold for tissue engineering in burns cases. Sample with $0,15 \%$ Aloe vera and $0,07 \%$ Achatina fulica sp mucus

\section{Acknowledgement}

Our gratitude are delivered to Laboratory of Material Chemistry and Physics, Faculty of Science and Technology Universitas Airlangga, Institute of Tropical Disease (ITD) Universitas Airlangga, Microbiology Laboratory Universitas Negeri Surabaya, Pharmacognosy Laboratory Faculty of Pharmacy Universitas Airlangga, National Institute of Nuclear Energy (BATAN) for the facilities.

\section{References}

[1] Li W. J., Shanti R. M., Tuan R. S. 2006. Electrospinning Technology for Nanofibrous Scafffolds in Tissue Engineering. Nanotechnologies for the Life Sciences, Vol. 9: Tissue, Cell and Organ Engineering. Ed. Kumar C. WileyVCH Verlag GmbH \& Co. KGaA, Germany. 9: 135-187.

[2] http://www.who.int/news-room/fact-sheets/detail/burns (Accessed on January 2nd 2017, 13: 45).

[3] Moenadjat, Y. 2000. Luka Bakar: Pengetahuan Klinik Praktis. Cetakan I. Farmedia, Jakarta.

[4] Humatcher, D. W. 2001. Scaffold Design and Fabrication Technologies for Engineering Tissues-state of the Art and Future Perspectives. J. Biomater. Sci. Polymer. 12: 107-124.

[5] Hoque, M., Enamul, Tamrin Nuge, Tshai Kim Yeow, Norshariza Nordinand, R. G. S. V. Prasad, 2016. Gelatin Based Scaffolds for Tissue Engineering - A Review. Polymers Research Journal. 9(1): 1935-2530.

[6] Vázquez Martin R, Brenda Vega-Ruiz, Rodrigo RamosZúñiga, Daniel Alexander Saldaña-Koppel, and Luis Fernando Quiñones-Olvera. 2015. Chitosan and Its Potential Use as a Scaffold for Tissue Engineering in Regenerative Medicine. Hindawi Publishing Corporation BioMed Research International. 1-15. 
[7] Lee, C. K. 2006. Immunomodulatory Activity. In Y. I. Park, S. K. Lee (Eds.). New Perspectives on Aloe. Springer Science, NY. 155-167.

[8] Otsuka - Futchino. 1993. Morphological Aspect of Achasin Treated Bacteria. J. Comp. Biochem, Physiol. 104C: 37-41.

[9] Dhandayuthapani, B., Yoshida, Y., Maekawa, T., Kumar, D. S. 2011. Polymeric Scaffolds in Tissue Engineering Application: A Review. Int. J. Polym. Sci. 1-19.

[10] O'Brien, F. J., Harley, B. A., Yannas, I. V., Gibson, L. 2005. The Effect of Pore Size on Cell Adhesion in Collagen-GAG Scaffolds. Biomaterials. 26: 433-441.

[11] Freyman, T. M., Yannas, I. V. and Gibson, L. J. 2001 Cellular Materials as Porous Scaffolds for Tissue Engineering. Prog. Mat Sci. 46: 273-82.

[12] Chen Gouping, Takashi Ushida and Tetsuya Tateishi. 2002. Scaffold Design for Tissue Engineering. WILEY-VCH Verlag $\mathrm{GmbH}$, Weinheim, Fed. Rep. of Germany.

[13] Kakkar, P. S. Verma, I. Manjubala, B. Madhan. 2014 Development of Keratin-chitosan-gelatin Composite Scaffold for Soft Tissue Engineering. Mater. Sci. Eng. 45: 343-347. http://dx.doi.org/10.1016/j.msec.2014.09.021.

[14] Angulo Daniel Enrique López, Sobral. Paulo José do Amaral. 2016. Characterization of Gelatin/chitosan Scaffold Blended with Aloe Vera and Snail Mucus for Biomedical Purpose. International Journal of Biological Macromolecules. 92: 645-653.

[15] Sanchez, S. H., Zuniga, R. R., Anda de, L. S., Dellamary, L. F., Castaneda, G. R., Jaimes, R. C., Espinoza, J. G. 2012. A New Bilayer Chitosan Scaffolding as a Dural Substitute: Experimental Evaluation. World Neurosurg. 77(3/4): 577582.

[16] Sung, H. J., Carson Meredith, Chad Johnson, Zorina, S. Galis. 2004. The Effect of Scaffold Degradation Rate on Three-dimensional Cell Growth and Angiogenesis. Biomaterials. 25: 5735-5742.
[17] Silva, S. S., Caridade, S. G., Mano, J. F., \& Reis, R. L. 2013. Effect of Crosslinking in Chitosan/aloe Vera-based Membranes for Biomedical Applications, Carbohydrate. Polymers. http://dx.doi.org/10.1016/j.carbpol.2013.06.022.

[18] Tan, Q., L. Songgang, J. Ren, Ch. Chen. 2011. Fabrication of Porous Scaffolds with a Controllable Microstructure and Mechanical Properties by Porogen Fusion Technique. Int. J. Mol. Sci. 12(2011): 890-904.

[19] Loh, Q. L., B. Choong. 2013. Three-dimensional Scaffolds' for Tissue Engineering Applications: Role of Porosity and Pore Size. Tissue Eng.: Part B. 19(6).

[20] Surjushe, A., Vasani, R., Saple, D. G. 2008, Aloe Vera: A Short Review. Indian J. Dermatol. 53: 163-166.

[21] Baruah, A., Bordoloi, M., Baruah, H. P. 2016. Aloe Vera: A Multipurpose Industrial Crop. Indust. Crops Prod. 94: 951963.

[22] Klein, A. D., Penneys, N. S. 1988. Aloe vera. J. Am. Acad. Dermatol. 18: 714-720.

[23] Rose Chellan, Jithendra Panneerselvam, Rajam Abraham Merlin, Kalaivani Tambiran, Mandal Asit Baran, 2013. Preparation and characterization of Aloe vera blended Collagen Chitosan Composite Scaffold for Tissue Engineering Applications. Journal of Applied Materials and Interfaces. 5(15): 7291-7298.

[24] Saarai, A., Kasparkova, V., Sedlacek, T., S áha, P. 2011. A Comparative Study of Crosslinked Sodium Alginate/Gelatin Hydrogels for Wound Dressing. Proceeding of the 4th WSEAS International Conference on Energy and Development, Corfu Island, Greece, 14-16 July 2011. 384-389.

[25] O'Brien, F. 2011. Biomaterials and Sca Olds for Tissue Engineering. Materials Today. 14(3).

[26] Evers Lars, H., Dhaval Bhavsarand Peter Maila "nder. 2010. The Biology of Burn Injury. Experimental Dermatology. 19: 777-783. 